Brief report

\title{
Psychopathology and functioning among children of treated depressed fathers and mothers
}

\author{
Daniel J. Pilowsky c,d,e,*, Priya Wickramaratne ${ }^{\text {c,e }}$, Ernest Poh ${ }^{c}$, Mariely Hernandez ${ }^{c}$, \\ Lisa A. Batten ${ }^{\mathrm{a}, \mathrm{b}}$, Martine F. Flament ${ }^{\mathrm{a}}$, Jonathan W. Stewart ${ }^{\mathrm{c}, \mathrm{e}}$, \\ Pierre Blier ${ }^{\mathrm{a}}$, Myrna M. Weissman ${ }^{\mathrm{c}, \mathrm{d}, \mathrm{e}}$ \\ ${ }^{a}$ University Of Ottawa Institute Of Mental Health Research, Ottawa, Ontario, Canada \\ ${ }^{\mathrm{b}}$ Carleton University, Ottawa, Ontario, Canada \\ ${ }^{\mathrm{c}}$ Division of Epidemiology at the New York State Psychiatric Institute, USA \\ d Department of Epidemiology at the Mailman School of Public Health at Columbia University, USA \\ e Department of Psychiatry of the College of Physicians and Surgeons at Columbia University, USA
}

\section{A R T I C L E I N F O}

\section{Article history:}

Received 30 October 2013

Received in revised form 13 April 2014

Accepted 14 April 2014

Available online 18 April 2014

\section{Keywords:}

Depressed fathers

Depressed mothers

Children of depressed parents

Major depressive disorder

\begin{abstract}
A B S T R A C T
Objective: Recent findings suggest that remissions of maternal depression are associated with decrease in offspring psychopathology. Little is known about the offspring effects of decrease in paternal depression. Method: The offspring of married fathers and married mothers were compared. The analysis was restricted to married parents to control for the confounding effect of single parenthood which was more prevalent among depressed mothers. At baseline all parents met criteria for major depressive disorder (MDD), and participated in a 3 month randomized controlled trial to treat depression with a 6 month follow-up. Married parents $(N=43)$ and their children aged 7-17 years $(N=78)$ were assessed independently through direct interviews of children and parents at baseline and followed for 9 months. Child assessors were blind to the clinical status of parents and uninvolved in their treatment.

Results: At baseline, children of depressed fathers, compared to children of depressed mothers, had significantly fewer psychiatric disorders ( $11 \%$ vs. $37 \% ; p=0.012)$ and less impairment as measured by the Columbia Impairment Scale (6.5 vs. 11.6; $p=0.009$ ). Over time, with treatment of parental depression, the prevalence of most child symptoms decreased among children of depressed mothers, but changed little among children of depressed fathers.

Limitations: The main limitation of the study is the small number of fathers and their offspring included in the study.

Conclusion: Maternal as compared to paternal depression had a greater impact on children. With treatment of parental depression the differential prevalence of child symptoms by parental gender narrowed over time. The clinical implication is that children may benefit from treatment of their depressed parents.
\end{abstract}

(c) 2014 Elsevier B.V. All rights reserved.

\section{Introduction}

Numerous studies have shown that children of depressed as compared to non-depressed parents have increased rates of depressive, anxiety and behavioral disorders (Beardslee et al., 2011; Weissman et al., 2006). Children of depressed fathers have increased rates of parent-child conflict and elevated rates of externalizing disorders (Ramchandani et al., 2005; Weitzman et al., 2011) similar to children of depressed mothers (Connell and Goodman, 2002). However, compared to paternal depression, the

\footnotetext{
* Corresponding author at: MSPH at Columbia University, Room R514, 722 West 168th Street, New York, NY 10032, USA. Tel.: +1 212 3046554; fax: + 19175918803 .

E-mail address: dp14@columbia.edu (D.J. Pilowsky).
}

offspring of depressed mothers may be at greater risk of developing internalizing disorders (Beardslee et al., 2003; Kane and Garber, 2004; Klein et al., 2005).

Remissions of parental depression are associated with decrease in offspring psychopathology (Garber et al., 2011; Pilowsky et al., 2008). However, the remission studies have usually focused on depressed mothers. This report focuses on psychopathology and functioning among children of treatment-seeking depressed fathers and mothers as the parents recover from depression.

\section{Methods}

Ethics Approval. This study was approved by the New York State Psychiatric Institute Institutional Review Board. 


\subsection{Sample}

The overall sample consisted of 93 index parents (82 mothers and 11 fathers) who entered a clinical trial ("Adult Study") and their 168 children aged 7-17 years (Batten et al., 2012). We previously reported on outcomes among children of depressed mothers (Weissman et al., in press). This report focuses on children of depressed fathers at baseline and during the 9 month follow-up interval. Adult Study participants were outpatients aged 18-65, with non-psychotic MDD recruited in New York City or Ottawa, Canada. They were randomized to one of three treatments (bupropion, escitalopram or both). After completion of the three month randomized clinical trial patients and their children were followed for an additional 6 months. We restricted the analysis to a sample of married depressed parents to prevent confounding by marital status since most single parents were female and maternal depression affects children of single and married or cohabitating mothers differently (Talati et al., 2007). None of the parents participating in the study were married to each other. The restricted sample included 9 fathers of 19 children and 34 mothers of 59 children. Overall there were 78 children.

Child assessments were conducted by independent assessors who knew that participating parents were depressed at baseline but did not have access to the parents' assessments. Parents and their children were assessed at baseline (i.e. at the onset of treatment of parental depression) and 1, 2, 3, 6 and 9 months after (Batten et al., 2012).

\subsection{Parental assessments}

\subsubsection{Hamilton Rating Scale for Depression $\left(H A M D_{17}\right)$}

$\mathrm{HAMD}_{17}$ is a clinician-rated scale used to assess severity and changes in depressive symptoms (Endicott et al., 1981; Hamilton, 1960, 1967; Kearns et al., 1982). The 17-item scale ranks symptoms from 0 (not present) to 4 (severe). A score of 7 or less was considered indicative of remission and response was defined as a $50 \%$ reduction of the baseline score.

\subsection{Child assessments}

Children were the responders for the Children's Depression Inventory (CDI), the Multidimensional Anxiety Scale for Children (MASC), and the Columbia Impairment Scale (CIS). Both children and parents were respondents for the K-SADS-PL. The Children's Global Assessment Scale (C-GAS) was completed by the assessor considering all data from the K-SADS-PL and all other assessments.

\subsubsection{KSADS-PL}

The Kiddie-Schedule for Affective Disorders and Schizophrenia, Present and Life-time version (KSADS-PL) was used to assess affective, anxiety, disruptive, and substance use Axis I DSM-IV disorders (Kaufman et al., 1997). Children and parents were interviewed separately.

\subsubsection{Child Global Assessment Scale (C-GAS)}

The C-GAS a clinician-rated measure of global functioning, provides an estimate of overall severity of disturbance (range, 0-100), with scores above 90 indicating superior functioning, and scores below 70 indicating impaired global functioning (Shaffer et al., 1983).

\subsubsection{Children's Depression Inventory (CDI)}

The CDI is a self-report measure of depressive symptoms for use with children and adolescents aged 7-17 years (Kovacs, 1981, 1992). Higher scores indicate more depressive symptoms.

\subsection{Columbia Impairment Scale (CIS)}

The CIS, a measure of impairment, taps four domains: interpersonal relations, psychopathology, job or school work, and use of leisure time in children (Bird et al., 1996, 1993).

\subsection{Multidimensional Anxiety Scale for Children (MASC)}

The MASC assesses four domains of anxiety in children and adolescents: physical symptoms, social anxiety, harm avoidance and separation/panic (March, 1997; March et al., 1997; March and Parker, 1999). Higher total and sub-scale scores indicate more anxiety symptoms.

\subsection{Data analysis}

All analyses were performed using SAS software, version 9.3. Differences in means of continuous variables for baseline characteristics of parents were determined using $t$ tests, while differences in the distribution of categorical variables were analyzed using contingency table analyses and associated Chi-square tests or Fisher's Exact Tests when counts were low. Differences in baseline psychopathology and functioning in children by parent gender were analyzed using linear mixed models for continuous outcomes and logistic regression (for binary outcomes) and Poisson regression (for outcomes that are counts) used in the framework of generalized estimating equations to adjust for correlation between siblings.

Differences in rates of parental response (defined as a $50 \%$ reduction of the baseline $\mathrm{HAMD}_{17}$ score) during the study period ( 9 months) were determined using logistic regression analysis with maternal/paternal response status as the binary outcome variable, gender of parent as the independent variable and including age of parents as a covariate. Differential effects of gender on change in parents' depressive symptoms were analyzed using linear mixed effects regression model analyses, which account for the nesting of time within person, to test linear and curvilinear (quadratic) trends over time.

Differential effects by parental gender on changes in child outcomes over the 9 month study period were investigated as follows: when the child outcome was a continuous variable, linear mixed effects regression models were fitted to the data with the child outcome variable as the dependent variable, parental gender and time (study week) as independent variables as well as an interaction term representing parental gender $x$ time. In addition, age and sex of child and site were included as covariates. A statistically significant interaction term indicates a differential effect of parent gender. Correlations between related measures over time as well as non-independence of observations in siblings were handled by including nested random effects in the model within subject nested within family (Betensky et al., 2000). When child outcomes were either binary variables (child diagnoses) or count variables (child symptoms), logistic regression (for binary outcomes) and Poisson regression (for outcomes that are counts) were used in the framework of generalized estimating equations to determine differential effects of parent gender on these outcomes. Repeated measures over time and non-independence of siblings were accounted for by using an independence correlation matrix, since the clusters are perfectly nested (repeated measures over time within siblings) (Singer, 1998). Potential confounding variables were handled as described for continuous outcomes. 


\section{Results}

There were no statistically significant differences in educational level, employment status, mean number of children per family, or household income between depressed married mothers $(N=34)$ and married fathers $(N=9)$ participating in the study. Although not statistically significant, the sample included more Hispanic mothers than fathers (1[11.1\%] and 12 [35.3\%] Hispanic fathers and mothers, respectively; $T=9.73 ; p<0.10$; data not shown). The average age of the 9 fathers was 43.6 years compared to 41.2 for the 34 mothers ( $p=0.86) ; 44.4 \%$ and $58.8 \%$ of fathers and mothers, respectively, were white $(p=0.6)$. Baseline clinical characteristics were also similar with baseline mean HAMD $_{17}$ scores of 22.7 and 21.8 , for fathers and mothers, respectively $(p=0.24)$. The mean age of the children $(N=78)$ was 11.3 years and over half $(53.8 \%)$ were in grades $1-6$. There were no statistically significant differences in gender $\left(\chi^{2}=1.73, \mathrm{df}=1, p=0.19\right)$ or age ( $\left.t=0.94, \mathrm{df}=76, p=0.348\right)$ between children of participating fathers and mothers. The mean age of children of participating mothers was $11.08(\mathrm{SD}=3.27)$, and of participating fathers was $11.89(\mathrm{SD}=3.21)$.

At baseline none of the children were receiving mental health treatment. At week 12 a mother (2.9\%) and no father reported that one of their children had been treated for emotional or behavioral problems. At week 24 two mothers (5.9\%) and no father, and at week 36 one father (11.1\%) and 2 mothers (5.9\%) reported that one of their children had been treated.

The HAMD 17 scores of fathers and mothers decreased between baseline and 6 month and leveled off thereafter (data not shown). A linear regression model fitted to the data showed a negative linear component (beta $=-1.09, t=-15.31 ; p<0.0001$ ) and a positive quadratic component (beta $=0.02, t=11.61 ; p<0.001$ ), suggesting that the HAM-D 17 scores decreased and then leveled off after 6 months. There were no significant differences in changes of $\mathrm{HAMD}_{17}$ scores over time between mothers and fathers $(F$-value $=0.93 ; \mathrm{DF}=1434 ; p=0.3366)$.

At baseline (Table 1), children of depressed married fathers, as compared to mothers, were less likely to have a psychiatric disorder ( $11 \%$ vs. $37 \%$; $p=0.012$ ), had a lower prevalence of $\mathrm{K}$ SADS symptoms, by child ( 0.2 vs. 1.2 symptoms; $p=0.063)$ and parental report ( 0.6 vs. 2.0 symptoms; $p=0.075)$, and were less impaired (CIS of 6.5 vs. 11.6; $p=0.009$ ). Anxiety symptoms, as reflected in MASC total scores, did not differ significantly.

Over the nine month follow-up interval there was a clear pattern, i.e. the prevalence of most child symptoms decreased (significantly or at the trend level) among children of treated depressed mothers, but not among children of depressed fathers (Table 2). The group by time interaction was significant only for CDI scores. Anxiety symptoms (see MASC total scores, Table 2) did not follow this pattern, i.e. symptoms decreased regardless of parental gender. By the end of the 9 month follow-up interval differences in the prevalence of psychopathological symptoms by parental gender narrowed.

\subsection{Remission of parental depression and child outcomes}

At the end of the 9 month follow up 5 of 9 fathers (55.6\%) and 25 of 34 mothers (73.5\%) had remitted. We compared outcomes in children of remitting fathers and mothers over time while controlling for child age, gender, site (New York City/Ottawa), and within family correlation (data not shown). All $p$ values provided here refer to the significance of the beta coefficient for the time trend over the 9 month follow-up. During this interval children of remitting mothers experienced a statistically significant decrease of depressive symptoms as reflected in CDI scores $(p<0.001)$, of parent-reported K-SADS symptoms $(p=0.002)$, MASC-social anxiety $(p=0.004)$, MASC-physical symptoms $(p=0.044)$ and MASC-
Table 1

Baseline psychopathology and global functioning among children of married depressed mothers and fathers. ${ }^{\mathrm{a}, \mathrm{b}}$

\begin{tabular}{|c|c|c|c|c|}
\hline $\begin{array}{l}\text { Child's current } \\
\text { diagnoses }\end{array}$ & $\begin{array}{l}\text { Children of fathers } \\
N=19 \\
\boldsymbol{N}(\%)\end{array}$ & $\begin{array}{l}\text { Children of } \\
\text { mothers } N=59 \\
N(\%)\end{array}$ & $\begin{array}{l}\text { Test } \\
\text { statistic }^{\mathrm{c}}\end{array}$ & $\begin{array}{l}p \\
\text { value }\end{array}$ \\
\hline \multicolumn{5}{|l|}{ Disorders } \\
\hline Mood $^{\mathrm{d}, \mathrm{e}}$ & $0(0 \%)$ & $7(12 \%)$ & 3.98 & 0.046 \\
\hline Anxiety & $1(5 \%)$ & $11(19 \%)$ & 2.00 & 0.158 \\
\hline Behavioral $^{\mathrm{f}}$ & $1(5 \%)$ & $13(22 \%)$ & 3.68 & 0.055 \\
\hline Substance & $0(0 \%)$ & $1(2 \%)$ & 1.37 & 0.242 \\
\hline \multicolumn{5}{|l|}{ Use $^{\mathrm{e}}$} \\
\hline Any Disorder & $2(11 \%)$ & $22(37 \%)$ & 6.29 & 0.012 \\
\hline \multicolumn{5}{|c|}{ Number of K-SADS symptoms, mean (SD) } \\
\hline $\begin{array}{c}\text { Child report } \\
\text { (range) }\end{array}$ & $\begin{array}{l}0.2(0.5) \\
(0-2)\end{array}$ & $\begin{array}{l}1.2(1.8) \\
(0-8)\end{array}$ & -1.92 & 0.063 \\
\hline $\begin{array}{l}\text { Parent report } \\
\text { (range) }\end{array}$ & $\begin{array}{l}0.6(1.2) \\
(0-4)\end{array}$ & $\begin{array}{l}2.0(3) \\
(0-14)\end{array}$ & -1.84 & 0.075 \\
\hline \multicolumn{5}{|c|}{ Symptoms and Impairment, mean (SD) } \\
\hline C-GAS score & $81.1(8.8)$ & $76.7(12.6)$ & 1.11 & 0.275 \\
\hline CDI score & $5.6(4.8)$ & $8.3(6.1)$ & -1.27 & 0.213 \\
\hline CIS score & $6.5(4.2)$ & $11.6(7.7)$ & -2.79 & 0.009 \\
\hline \multicolumn{5}{|c|}{ MASC scores, mean (SD) } \\
\hline Total & 44.1(17) & $46.7(13.8)$ & 0.38 & 0.709 \\
\hline
\end{tabular}

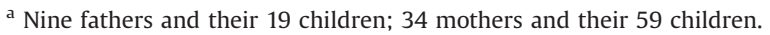

${ }^{\mathrm{b}}$ Unadjusted rates and means reported. Models were adjusted for child age and gender, site, and within family correlation.

${ }^{c}$ Chi-square or Fisher's exact test for percent comparisons and $t$ statistic for comparisons of means.

d Includes major depressive disorder, dysthymic disorder, and depressive disorder not otherwise specified (there were no children receiving bipolar diagnoses).

e Models did not converge due to low cell counts and they were not adjusted for covariates.

${ }^{\mathrm{f}}$ Includes ADHD, oppositional-defiant disorder, and conduct disorder.

Total ( $p=0.001)$, as well as improved functioning as measured by the CIS $(p<0.001)$. They also experienced marginally significant changes of the MASC-separation/panic score $(p=0.053)$, and child reported K-SADS symptoms $(p=0.076)$. Over the same interval children of remitting fathers experienced only two statistically significant changes, i.e. MASC-Physical symptoms $(p=0.008)$, and MASC- total $(p=0.006)$, and a marginally significant change, i.e. child-reported K-SADS symptoms $(p=0.067)$. These changes were in the expected direction (less psychopathology or better functioning). There were no significant changes in C-GAS scores among children of remitting fathers or mothers. We compared the effect of remission between children of remitting fathers and remitting mothers (as estimated by examining the significance of the group by time interaction coefficients). There were no statistically significant differences for any of the child outcomes under consideration. In sum, over the nine months follow up there were several significant changes in the expected direction among children of remitting mothers, and few significant changes among children of remitting fathers, but the effect of remission did not differ significantly between children of remitting fathers and remitting mothers.

We also examined changes in children's outcomes among children of non-remitting fathers and non-remitting mothers. The only statistically significant change was a decrease of MASC total scores among children of non-remitting mothers $(p=0.049)$. The effect of non-remission did not differ significantly among children of non-remitting fathers and non-remitting mothers ( $p$ values were not statistically significant for group by time interactions for any of the child outcome examined). These results should be viewed cautiously given the small number of remitting and non-remitting fathers. 
Table 2

Child psychopathology and functioning among children of treated depressed parents. ${ }^{\text {a,b }}$

\begin{tabular}{|c|c|c|c|c|c|c|c|c|}
\hline \multirow[t]{2}{*}{ Child outcome } & \multirow[t]{2}{*}{ Baseline } & \multicolumn{5}{|l|}{ Month } & \multirow[t]{2}{*}{$\beta$} & \multirow[t]{2}{*}{$p$} \\
\hline & & 1 & 2 & 3 & 6 & 9 & & \\
\hline Any diagnosis & $N(\%)$ & $N(\%)$ & $N(\%)$ & $N(\%)$ & $N(\%)$ & $N(\%)$ & & \\
\hline Fathers ${ }^{c}$ & $2(10.5)$ & $0(0)$ & $0(0)$ & $0(0)$ & $0(0)$ & $0(0)$ & & \\
\hline Mothers ${ }^{c}$ & $22(37.3)$ & $13(22)$ & $15(25.4)$ & $12(20.3)$ & $9(15.3)$ & $11(18.6)$ & & \\
\hline \multicolumn{9}{|l|}{ Group-by-time } \\
\hline Mean at each time point (month) & & & & & & & Time trend & \\
\hline \multicolumn{9}{|l|}{ KSADS Symptoms - child report } \\
\hline Fathers & 0.21 & 0 & 0.19 & 0.08 & 0 & 0.27 & 0.013 & 0.741 \\
\hline Mothers & 1.2 & 0.96 & 1.26 & 0.9 & 0.61 & 0.92 & -0.012 & 0.083 \\
\hline Group-by-time & & & & & & & & 0.572 \\
\hline \multicolumn{9}{|l|}{ KSADS symptoms - parent report } \\
\hline Fathers & 0.58 & 0.06 & 0.19 & 0 & 0 & 0.18 & -0.06 & 0.422 \\
\hline Mothers & 1.97 & 1.51 & 1.76 & 1.16 & 0.94 & 1.06 & -0.02 & 0.001 \\
\hline Group-by-time & & & & & & & & 0.539 \\
\hline \multicolumn{9}{|l|}{ CGAS } \\
\hline Fathers & 81.11 & 85.63 & 86.5 & 88.69 & 88.69 & 85.55 & 0.077 & 0.381 \\
\hline Mothers & 76.69 & 78.33 & 77.44 & 78.94 & 79.27 & 78.17 & 0.002 & 0.960 \\
\hline Group-by-time & & & & & & & & 0.445 \\
\hline \multicolumn{9}{|l|}{ CDI } \\
\hline Fathers & 5.61 & 5.25 & 5 & 6 & 4.85 & 8.09 & 0.032 & 0.421 \\
\hline Mothers & 8.34 & 6.58 & 5.98 & 5.4 & 4.88 & 5.04 & -0.065 & 0.001 \\
\hline Group-by-time & & & & & & & & 0.027 \\
\hline \multicolumn{9}{|l|}{ CIS } \\
\hline Fathers & 6.47 & 5.69 & 6.81 & 6.92 & 5.38 & 6.27 & -0.017 & 0.681 \\
\hline Mothers & 11.64 & 9.84 & 9.04 & 7.46 & 7.62 & 8.67 & -0.066 & 0.003 \\
\hline Group-by-time & & & & & & & & 0.308 \\
\hline \multicolumn{9}{|l|}{ MASC - total } \\
\hline Fathers & 44.05 & 39.44 & 34.69 & 38.62 & 31.23 & 30.09 & -0.272 & 0.011 \\
\hline Mothers & 46.71 & 42.55 & 39.78 & 38.58 & 36.78 & 38.13 & -0.198 & $<0.001$ \\
\hline Group-by-time & & & & & & & & 0.529 \\
\hline
\end{tabular}

a Unadjusted rates and means reported. All models were adjusted for child age, gender, site, and within family correlation.

${ }^{\mathrm{b}}$ Nine fathers and their 19 children; 34 mothers and their 59 children.

${ }^{\mathrm{c}}$ Models did not converge. Thus, betas and group by time interactions could not be estimated.

\section{Discussion}

Depression among treatment-seeking currently depressed fathers were associated with a lower prevalence of offspring psychiatric symptoms when compared to the offspring of currently depressed mothers. This finding concurs with the results of a recent study indicating that children of fathers with depressive symptoms had substantially lower emotional and behavioral problems than children of mothers with these symptoms (Weitzman et al., 2011). Weitzman et al.'s study has limitations, i.e. child status was assessed using parental report alone, and parental depression was assessed using a two-question instrument. In spite of these limitations it has the advantage of having a large sample $(N=21,993)$. Thus, a large sample study with limited child and parent assessments, and the present study, with multiple reliable instruments and direct child interviews but a small sample of fathers, converge to show that paternal depression, compared to maternal depression, is associated with fewer offspring psychopathological symptoms and less impaired functioning. Fathers are difficult to recruit for this type of study (Garber et al., 2011), at least in part because the prevalence of depression is lower in men and they are less likely to seek treatment (Accortt et al., 2008; Kessler et al., 2003). The differential impact of parental depression, noted at baseline, is likely related to the greater amount of time children spend with their mothers (Cowan et al., 2009; Pleck and Masciadrelli, 2004), although this was not measured in this study.
Over time, with treatment of parental depression, psychiatric symptoms did not decrease significantly among children of depressed fathers, except for anxiety symptoms which decreased in all children regardless of parental gender. In contrast, symptoms of depression (CDI) and anxiety (MASC), as well as overall symptoms (K-SADS-PL), decreased among children of depressed mothers. Although the absence of significant change among children of treated fathers may have resulted from limited statistical power, the data suggest a pattern wherein children of depressed fathers changed little and children of depressed mothers became less symptomatic. These children came a long way towards catching up with children of treated depressed fathers nine months after the initiation of treatment of parental depression. It is noteworthy that a higher percentage of mothers (73.5\%) than fathers (55.6\%) experienced a remission of their depression during the 9-month follow up interval.

Significant limitations are noteworthy. We do not have information about the amount of time mothers and fathers spent with their children. The apparently modest impact of paternal depression on child outcomes may be due to fathers spending less time with their children compared to mothers. The number of fathers we were able to recruit was small and we do not know whether they are representative of depressed fathers in the cities where the study was done. Other investigators have experienced similar difficulties recruiting depressed fathers to participate in offspring-focused treatment studies as discussed elsewhere (Garber et al., 2011) and therefore findings about children of 
depressed fathers are noteworthy. Thus, estimates of outcomes in these children are unstable and statistical power to examine differences in outcomes between children of depressed fathers and mothers was limited. While statistically significant differences are meaningful, the absence of differences between mothers and fathers and their children may simply reflect limited statistical power to detect these differences. Furthermore, a floor effect may explain the lack of appreciable changes among children of depressed fathers over time. We know little about the spouses of index parents. Having two depressed parents, compared to one, may have a greater child impact (Beardslee et al., 1998). A noteworthy strength of this study is the direct interview of children, thus overcoming the potential shared informant bias that arises when depressed parents report about themselves and about their children.

\section{Role of funding source}

The funding sources did not contribute to the preparation of the manuscript. The manuscript was not reviewed by the funding sources and was not submitted for their approval.

\section{Conflict of interest}

No conflict declared.

\section{Acknowledgments}

This study was funded by the following grants: MH082255 Parental Remission of Depression and Child Psychopathology (MMW, PI); MH076961-01A2 (JWS, PI); MH077285-01A2 (PB, PI).

\section{References}

Accortt, E.E., Freeman, M.P., Allen, J.J., 2008. Women and major depressive disorder: clinical perspectives on causal pathways. J. Women's Health 17, 1583-1590.

Batten, L.A., Hernandez, M., Pilowsky, D.J., Stewart, J.W., Blier, P., Flament, M.F., Poh, E., Wickramaratne, P., Weissman, M.M., 2012. Children of treatment-seeking depressed mothers: a comparison with the sequenced treatment alternatives to relieve depression (STAR*D) child study. J. Am. Acad. Child Adolesc. Psychiatry $51,1185-1196$.

Beardslee, W.R., Gladstone, T.R., Wright, E.J., Cooper, A.B., 2003. A family-based approach to the prevention of depressive symptoms in children at risk: evidence of parental and child change. Pediatrics 112, e119-e131.

Beardslee, W.R., Gladstone, T.R.G., O'Connor, E.E., 2011. Transmission and prevention of mood disorders among children of affectively ill parents: a review. J. Am. Acad. Child Adolesc. Psychiatry 50, 1098-1109.

Beardslee, W.R., Versage, E.M., Gladstone, T.R., 1998. Children of affectively ill parents: a review of the past 10 years. J. Am. Acad. Child Adolesc. Psychiatry 37, 1134-1141.

Betensky, R.A., Talcott, J.A., Weeks, J.C., 2000. Binary data with two, non-nested sources of clustering: an analysis of physician recommendations for early prostate cancer treatment. Biostatistics 1, 219-230.

Bird, H.R., Andrews, H., Schwab-Stone, M., Goodman, S., Dulcan, M., Richters, J., Rubio-Stipec, M., Moore, R.E., Chiang, P.-H., Hoven, C., Canino, G., Fisher, P., Gould, M.S., 1996. Global measures of impairment for epidemiologic and clinical use with children and adolescents. Int. J. Methods. Psychiatr. Res. 6, 295-307.

Bird, H.R., Shaffer, D., Fisher, P., Gould, M.S., et al., 1993. The Columbia Impairment Scale (CIS): pilot findings on a measure of global impairment for children and adolescents. Int. J. Methods Psychiatr. Res. 3, 167-176.

Connell, A.M., Goodman, S.H., 2002. The association between psychopathology in fathers versus mothers and children's internalizing and externalizing behavior problems: a meta-analysis. Psychol. Bull. 128, 746-773.
Cowan, P.A., Cowan, C.P., Pruett, M.K., Pruett, K., Wong, J.J., 2009. Promoting fathers' engagement with children: preventive interventions for low-income families. J. Marriage Fam. 71, 663-679.

Endicott, J., Cohen, J., Nee, J., Fleiss, J., Sarantakos, S., 1981. Hamilton Depression Rating Scale. Extracted from regular and change versions of the schedule for affective disorders and schizophrenia. Arch. Gen. Psychiatry 38, 98-103.

Garber, J., Ciesla, J.A., McCauley, E., Diamond, G., Schloredt, K.A., 2011. Remission of depression in parents: links to healthy functioning in their children. Child Dev. $82,226-243$.

Hamilton, M., 1960. A rating scale for depression. J. Neurol. Neurosurg. Psychiatry 23, 56-62.

Hamilton, M., 1967. Development of a rating scale for primary depressive illness. Br. J. Soc. Clin. Psychol. 6, 278-296.

Kane, P., Garber, J., 2004. The relations among depression in fathers, children's psychopathology, and father-child conflict: a meta-analysis. Clin. Psychol. Rev. 24, 339-360.

Kaufman, J., Birmaher, B., Brent, D., Rao, U., Flynn, C., Moreci, P., Williamson, D., Ryan, N., 1997. Schedule for affective disorders and schizophrenia for schoolage children-present and lifetime version (K-SADS-PL): initial reliability and validity data. J. Am. Acad. Child Adolesc. Psychiatry 36, 980-988.

Kearns, N.P., Cruickshank, C.A., McGuigan, K.J., Riley, S.A., Shaw, S.P., Snaith, R.P., 1982. A comparison of depression rating scales. Br. J. Psychiatry 141, 45-49.

Kessler, R.C., Berglund, P., Demler, O., Jin, R., Koretz, D., Merikangas, K.R., Rush, A.J., Walters, E.E., Wang, P.S., 2003. National Comorbidity Survey Replication, 2003. The epidemiology of major depressive disorder: results from the National Comorbidity Survey Replication (NCS-R). JAMA 289, 3095-3105.

Klein, D.N., Lewinsohn, P.M., Rohde, P., Seeley, J.R., Olino, T.M., 2005. Psychopathology in the adolescent and young adult offspring of a community sample of mothers and fathers with major depression. Psychol. Med. 35, 353-365.

Kovacs, M., 1981. Rating scales to assess depression in school-aged children. Acta Paedopsychiatr.: Int. J. Child Adolesc. Psychiatry 46, 305-315.

Kovacs, M., 1992. The Children's Depression Inventory Manual. Multi-Health Systems, Toronto, ON, Canada.

March, J., 1997. Manual for the Multidimensional Anxiety Scakle for Children (MASC). Multi-Health Systems, Toronto, ON, Canada.

March, J.S., Parker, J.D., Sullivan, K., Stallings, P., et al., 1997. The multidimensional anxiety scale for children (masc): factor structure, reliability, and validity. J. Am. Acad. Child Adolesc. Psychiatry 36, 554-565.

March, J.S., Parker, J.D.A., 1999. The Multidimensional Anxiety Scale for Children (MASC), The Use of Psychological Testing for Treatment Planning and Outcomes Assessment, 2nd ed. Lawrence Erlbaum Associates Publishers, Mahwah, NJ, USA, pp. 299-322.

Pilowsky, D.J., Wickramaratne, P., Talati, A., Tang, M., Hughes, C.W., Garber, J., Malloy, E., King, C., Cerda, G., Sood, A.B., Alpert, J.E., Trivedi, M.H., Fava, M., Rush, A.J., Wisniewski, S., Weissman, M.M., 2008. Children of depressed mothers 1 year after the initiation of maternal treatment: findings from the STARD-child study. Am. J. Psychiatry 165, 1136-1147.

Pleck, J.H., Masciadrelli, B.P., 2004. Paternal Involvement by U.S. Residential Fathers: Levels, Sources, and Consequences, The Role of the Father in Child Development, 4th ed. John Wiley \& Sons Inc, Hoboken, NJ, USA, pp. 222-271.

Ramchandani, P., Stein, A., Evans, J., O'Connor, T.G., 2005. ALSPAC Study Team, 2005. Paternal depression in the postnatal period and child development: a prospective population study. Lancet 365, 2201-2205.

Shaffer, D., Gould, M.S., Brasic, J., Ambrosini, P., Fisher, P., Bird, H., Aluwahlia, S., 1983. A children's global assessment scale (CGAS). Arch. Gen. Psychiatry. 40, $1228-1231$.

Singer, J.D., 1998. Using SAS PROC MIXED to fit multilevel models, hierarchical models, and individual growth models. J. Educ. Behav. Stat. 24, 323-355.

Talati, A., Wickramaratne, P.J., Pilowsky, D.J., Alpert, J.E., Cerda, G., Garber, J., Hughes, C.W., King, C.A., Malloy, E., Sood, A., Verdeli, H., Trivedi, M.H., Rush, A., Weissman, M.M., 2007. Remission of maternal depression and child symptoms among single mothers: a STAR*D-child report. Soc. Psychiatry. Psychiatr. Epidemiol. 42, 962-971.

Weissman, M.M., Wickramaratne, P., Nomura, Y., Warner, V., Pilowsky, D., Verdeli, H., 2006. Offspring of depressed parents: 20 years later. Am. J. Psychiatry 163, 1001-1008.

MM Weissman, P Wickramaratne, DJ Pilowsky, E Poh, M Hernandez, LA Batten, MF Flament, JW Stewart, P Blier. The effects on children of depressed mothers' remission over 9 months. Psychological Medicine, http://dx.doi.org/10.1017/ S003329171400021X, in press.

Weitzman, M., Rosenthal, D.G., Liu, Y.-H., 2011. Paternal depressive symptoms and child behavioral or emotional problems in the United States. Pediatrics 128, 1126-1134. 